\title{
Investigation of the effect of dipyrone on cells isolated from intervertebral disc tissue
}

\author{
FERIDE SINEM AKGUN ${ }^{1}$, DUYGU YASAR SIRIN ${ }^{2}$, IBRAHIM YILMAZ $^{3}$, NUMAN KARAARSLAN $^{4}$, \\ HANEFI OZBEK ${ }^{3}$, ABDULLAH TALHA SIMSEK ${ }^{4}$, YASIN EMRE KAYA ${ }^{5}$, NECATI KAPLAN ${ }^{6}$, \\ YENER AKYUVA $^{7}$, TEZCAN CALISKAN ${ }^{4}$ and OZKAN ATES ${ }^{8}$ \\ ${ }^{1}$ Department of Emergency Medicine, School of Medicine, Istanbul Maltepe University, Istanbul 34843; \\ ${ }^{2}$ Department of Molecular Biology and Genetics, Faculty of Arts and Sciences, Namik Kemal University, \\ Tekirdag 59100; ${ }^{3}$ Department of Medical Pharmacology, School of Medicine, Istanbul Medipol University, \\ Istanbul 34810; ${ }^{4}$ Department of Neurosurgery, School of Medicine, Namik Kemal University, Tekirdag 59100; \\ ${ }^{5}$ Department of Orthopedics and Traumatology, School of Medicine, Abant Izzet Baysal University, Bolu 14000; \\ ${ }^{6}$ Department of Neurosurgery, Corlu Reyap Hospital, Istanbul Rumeli University, Tekirdag 59680; \\ ${ }^{7}$ Department of Neurosurgery, Gaziosmanpasa Taksim Training and Research Hospital, Istanbul 34433; \\ ${ }^{8}$ Department of Neurosurgery, Istanbul Koc University Hospital, Istanbul Koc University, Istanbul 34010, Turkey
}

Received October 4, 2018; Accepted February 28, 2019

DOI: $10.3892 /$ etm.2019.7576

\begin{abstract}
The present study aimed to evaluate the effects of dipyrone, an indispensable analgesic, anti-pyretic and anti-spasmodic used in emergency departments, on nucleus pulposus and annulus fibrosus cells in vitro. After surgical biopsy, primary cell cultures were prepared from intact intervertebral disc tissues. Dipyrone was administered to the cultures in the experimental groups except for the control group. The data obtained were statistically evaluated. The proliferation was identified to be suppressed via MTT analysis. The gene expression profile of the intervertebral disc cells in the dipyrone-treated groups was significantly changed. The expression of chondroadherin, cartilage oligo matrix protein, interleukin-1 $\beta$ and metalloproteinase (MMP)-19 genes were decreased, but MMP-13 and MMP-7 genes expressions were increased, as determined via reverse transcription-quantitative PCR. AO/PI staining revealed that no apoptotic or other type of cell death was detectable after administration of dipyrone does not mean that the drug is innocuous. The occurrence of cellular senescence and/or the halt of cell proliferation may also be important mechanisms underlying the adverse inhibitory effects of dipyrone. Therefore, prior to administering dipyrone in clinical practice, all possible adverse effects of this drug should be considered.
\end{abstract}

Correspondence to: Dr Numan Karaarslan, Department of Neurosurgery, School of Medicine, Namik Kemal University, 1-14 Campus Street, Tekirdag 59100, Turkey

E-mail: numikara@yahoo.com

Key words: annulus fibrosus, dipyrone, intervertebral disc tissue, metamizole, nucleus pulposus, primary cell culture

\section{Introduction}

Metamizole sodium (dipyrone) is a pyrazoline-derived non-steroidal anti-inflammatory drug (NSAID) and non-opioid analgesic. Despite its low inhibitory effect on the enzyme cyclooxygenase, as well as its low anti-inflammatory effect, it has a marked analgesic effect (1). The analgesic properties of dipyrone contribute to its effects in afferent fibers, the spinal cord and periaqueductal gray matter. It also has an anti-pyretic and anti-spasmodic effect in vivo (1).

Of note, dipyrone is easily soluble in water. Therefore, its pharmaceutical application is simple, e.g. preparation of an injectable solution. When administered orally, dipyrone is non-enzymatically and rapidly converted to its active metabolite, 4-methylamino-antipyrine (4-MAA), in the acidic contained in the stomach. It is then absorbed through the gastrointestinal tract. When administered intravenously, it is converted to 4-MAA in the peripheral blood (1).

Numerous studies have discussed whether the analgesic effects of NSAIDs are tolerable, similar to opioid tolerance. Apart from its frequent use in clinical practice, it is generally accepted that the anti-nociceptive effects of NSAIDs lose their efficacy. Based on this consensus, dipyrone is also preferred as a prototype for NSAIDs in studies (1), demonstrating that tolerance to NSAIDs may be developed.

The use of dipyrone has been banned in the USA and certain European countries for allegedly causing agranulocytosis in the bone marrow and fluid/electrolyte imbalance (2). However, in numerous countries, it is still frequently prescribed in neurosurgery clinics (3) or is administered systemically in emergency departments (4). Long-term use of dipyrone loses efficacy to analgesic effects; this has been identified in the last few years as an important problem (1). Significant resistance, including the requirement to increase the dosage and thus the adverse effects, arise over long-term use. 
In the literature, the side effects and/or adverse events associated with dipyrone have been described as follows: a) Blood disorders, including shock and agranulocytosis, leukopenia and thrombocytopenia; b) high fever, chills, sore throat and difficulty swallowing; and c) inflammatory lesions in the mouth, nose, throat, genital and anal regions. However, its effects on intervertebral disc tissue cells, including nucleus pulposus (NP) or annulus fibrosus (AF) cells, have not been indicated in studies with high evidential value.

No veins, lymph or nerves are present in intervertebral disc tissue, just as in cartilage tissue. Instead, disc tissue is fed by synovial fluid. Since the outer layer of the synovial tissue is thicker, the drugs first diffuse from the synovial tissue to the synovial fluid. Subsequently, a second diffusion occurs from the synovial fluid to the disc tissue. Certain studies have indicated that drugs containing the pyrazole moiety, including dipyrone, pass into the synovial fluid of model rats with complete Freund's adjuvant-induced chronic arthritis (5).

Certain drugs may accumulate in numerous tissues of the body, including the synovial fluid compartments and the intervertebral disc tissue $(6,7)$. As a result of developments in pharmaceutical technology and regenerative medicine, the toxicity of drugs at the molecular level and the repair of the damaged tissues continue to be the subject of numerous studies. In such studies, apart from the drug's effect on the cell viability and proliferation, changes in the gene expression levels of certain proteins or specific biomarkers within the anabolic and/or catabolic pathways in tissues have also been investigated 6,7). However, to the best of our knowledge, no previous study has examined whether dipyrone damages non-degenerate, intact intervertebral disc tissue at the pharmaco-molecular level with high evidential value.

The present study investigated the effect of dipyrone on AF/NP cells. Primary cultures obtained from intact AF/NP tissues were used, and dipyrone was administered to these cultures for 20 days. The cell viability and proliferation of AF/NP cells and toxicity of dipyrone were analyzed in vitro. In addition, the gene expression levels of chondroadherin (CHAD), cartilage oligo matrix protein (COMP), matrix metalloproteinase 7 (MMP-7), MMP-13 and MMP-19, as well as interleukin-1 $\beta$ (IL-1 $\beta$ ) were examined using reverse transcription-quantitative polymerase chain reaction (RT-qPCR). No apoptotic death was observed in the dipyrone-treated AF/NP cell cultures. However, the cell proliferation was inhibited and the cells lost their specific morphology. In addition, changes in gene expression were observed in parallel with the changes in cell morphology.

\section{Materials and methods}

Study design. Analyses were repeated three times in total to minimize any experimental errors. The resection of the intervertebral disc tissues was performed by the same surgeons. While the cell cultures from primary human intervertebral disc tissue were established by the same researchers, the molecular analyses performed after the drug administration to the cultures were also performed by the same researchers. Researchers who performed the analyses did not know which drug was applied to which cell culture group, or which freshly prepared culture medium was applied to which cell culture group. While researchers performed the analyses, they were blinded to the experimental group identities.

Primary cell cultures of human intervertebral disc tissue were established from surgically resected tissues. Subsequently, all analyses were performed using cell samples from a non-drug-administered control group and drug-administered groups. The data obtained were then statistically evaluated.

Materials and reagents. Disposable cell culture materials were purchased from Biosorfa (Zhongguan, China; cat. no. SCD-11-035). FG-Microplate 96-well plates (cat. no. 4346906), fetal bovine serum (FBS; cat. no. 10500064), L-glutamine (cat. no. 25030024), penicillin-streptomycin $10,000 \mathrm{U} / \mathrm{ml}$ (cat. no. 15140122) and amphotericin B (250 UG/ml, cat. no. 12183018) were obtained from Thermo Fisher Scientific, Inc. (Waltham, MA, USA).

The pharmacological agent containing dipyrone used in the experiments was Novalgin Ampul in the form of $0.5 \mathrm{~g} / \mathrm{ml}$ ampoules. It was procured from Sanofi S.A. (Paris, France). The commercial kit used to examine the cell viability and proliferation to analyze toxicity was the Vybrant MTT cell proliferation assay (cat. no. V13154; Thermo Fisher Scientific, Inc.). The ELISA with which spectrophotometric analysis was performed was the Mindray MR 96A, PRC (Georgia Tech, Atlanta, GA, USA).

A PureLink ${ }^{\mathrm{TM}}$ RNA Mini kit (cat. no. 15290018; Thermo Fisher Scientific, Inc.) was used for RNA isolation, and a high-capacity complementary (c)DNA RT kit (cat. no. 4368814; Thermo Fisher Scientific, Inc.) was used to obtain cDNA. The following assays were also purchased from Thermo Fisher Scientific, Inc., to determine the mRNA expression of various genes in all experimental groups: $\operatorname{TaqMan}^{\circledR}$ gene expression assays (cat. no. 4331182), CHAD TaqMangeneexpressionassays(cat.no.4331182),COMPTaqMan gene expression assays (cat. no. 4331182), MMP-7 TaqMan gene expression assays (cat. no. 4331182), MMP-13 TaqMan gene expression assays (cat. no. 4331182), MMP-19 TaqMan gene expression assays (cat. no. 4331182), IL-1 $\beta$ TaqMan gene expression assays (cat. no. 4331182), internal control genes (housekeeping genes- $\beta$-actin) and Taqman Fast Advanced MMix 5ml (cat. no. 4444557).

Case selection criteria. Patients with a pyrazoline allergy, certain metabolic diseases (e.g., hepatic porphyria), congenital glucose-6-phosphate-dehydrogenase deficiency, blood dysregulation, hypersensitivity or intolerance to drugs containing pharmacological agents, including metamizole, isopropyl aminophenazone, propyphenazone, phenazone and phenylbutazone, were excluded from the study. If the tissues of these patients had been included in the study, it would not have been possible to determine whether the results on cytotoxicity or changes in cell morphology were due to dipyrone or to cell cultures obtained from the tissues of these patients. Similarly, the tissues of patients with a history of alcohol consumption or those using cyclosporine in the last three weeks were not included in the study, as the toxicity of dipyrone in these cases may have been affected by adverse drug synergism with alcohol or cyclosporine, which may accumulate in tissues. This may have adversely affected the results of the study. 
Resection of the tissues via surgery and preparation of the primary cell cultures. Non-degenerate healthy disc material (intact NP and AF tissue) was obtained as surplus surgical material from 3 male (age range, 25-31 years; mean age, 28) and 3 female patients (age range, 29-30 years; median age, 29.33 years). Subsequently, human primary intervertebral disc cell cultures were established individually according to standard protocols $(6,7)$. Physical and neurological examinations were performed on patients referred to the emergency department with the complaint of spinal trauma. Direct radiography, spinal-computed tomography scan and magnetic resonance imaging examinations were performed for possible spinal trauma localization. After these examinations, surgical intervention was planned in patients with spinal instability, traumatic intervertebral disc herniation and spinal cord compression.

All patients were placed in the prone position under endotracheal general anesthesia. Surgical field antisepsis was provided with $10 \%$ povidone-iodine solution and the area was covered in a sterile drape. After the skin was perforated with a median incision, paravertebral muscles were dissected subperiosteally. Neural decompression, traumatic disc excision and subsequent stabilization with the transpedicular screw-rod system were performed (6,7).

Under aseptic conditions at $4^{\circ} \mathrm{C}$, disc and granulation tissues were transferred to the laboratory in a culture medium [Dulbecco's modified Eagle's medium (DMEM; Gibco; Thermo Fisher Scientific, Inc., Waltham, MA, USA) supplemented with $1 \%$ penicillin-streptomycin, $15 \%$ FBS and $1 \%$ L-glutamine]. Tissue samples were irrigated with a $0.9 \%$ isotonic sodium chloride solution in the laminar flow cabinet and clarified from the red blood cells. Next, tissues were dissected into $0.4 \mathrm{~cm}^{3}$ pieces, washed in Hank's balanced salt solution and transferred to Falcon tubes. A total of $0.375 \mathrm{mg}$ Collagenase type II enzyme (Gibco; Thermo Fisher Scientific, Inc.) dissolved in complete medium was added to each tube and the samples were incubated with $5 \%$ $\mathrm{CO}_{2}$ at $37^{\circ} \mathrm{C}$ overnight. Next, the samples were centrifuged at $161 \mathrm{x} \mathrm{g}$ for $10 \mathrm{~min}$ at $37^{\circ} \mathrm{C}$ The cell pellets obtained were re-suspended by adding cell culture medium, transferred to T75 flasks and incubated to obtain primary cell cultures. Cells were counted in the presence of Trypan blue. Later, they were transferred to 96 -well plates at $1.6 \times 10^{4}$ cells/well for MTT analysis, to 24 -well plates at $4.3 \times 10^{4}$ cells/well for inverted microscopy and petri dishes at $5.1 \times 10^{6}$ cells/dish for acridine orange (AO)/propidium iodide (PI) analysis and for RNA isolation. They were then incubated for $24 \mathrm{~h}$ in an incubator with a humidified atmosphere containing $5 \% \mathrm{CO}_{2}$ at $37^{\circ} \mathrm{C}$. After the incubation period, dipyrone was administered to the cell cultures.

Application of dipyrone to the cultures. The major stock solution was freshly prepared as $0.5 \mathrm{~g} / \mathrm{ml}$ of dipyrone in DMEM in a flow cabinet. Subsequently, the major stock solutions were subjected to color coding, which enabled researchers to be blinded to the analyses. Dipyrone was applied to human primary NP/AF cell cultures at the final concentration of $250 \mu \mathrm{M}$. In another experiment, dipyrone was applied to the cultures at concentrations of 1, 50, 100, 250, 500 and $1,000 \mu \mathrm{M}$.
Cell proliferation was previously reported to stop completely in cultures where dipyrone at concentrations of $>250-300 \mu \mathrm{M}$ was applied (8). Therefore, dipyrone was applied at concentrations allowing for proliferation. Group I was prepared to resemble control group cells. The cells in this group were composed of cells obtained from healthy non-degenerated tissues [intact (i) AF/NP]. No drugs were administered to the cells in Group I. The cells forming the study group were Group II, in which human primary iAF/NP culture cells were cultivated with dipyrone at a concentration of $250 \mu \mathrm{M}$ for 20 days.

Inverted/fluorescence microscopy analysis. Cell morphology and confluency were observed using an inverted light microscope (Olympus CKX41; Olympus, Tokyo, Japan). Microphotographs of cell organization were obtained and analyzed during the confocal/contrast phase prior to and after dipyrone applications by Olympus Cell Soft Imaging System software (Olympus Corporation; version, Cell^A5.1). For further analysis of cell organization and characterization, cultures were stained with Giemsa (GS500; Sigma-Aldrich; Merck KGaA, Germany) and examined. A fluorescent microscope (DM 2500; Leica Microsystems, Wetzlar, Germany) was used for AO/PI analysis. Photomicrographs of the cells were obtained prior to and during dipyrone applications, and the images were evaluated using Cytovision Capture Station imaging software (version 7.0; Genetix; Leica Microsystems).

Analysis of cell viability, toxicity and proliferation by MTT assay. Viable cells digested the tetrazolium rings of MTT with their active mitochondrial dehydrogenase enzymes to generate formazan crystals. Unlike viable cells, dead cells did not form these formazan crystals $(6,7)$. The density of the resulting formazan crystals was detected with a spectrophotometer. Viability tests were performed using a commercial MTT kit. MTT analyses of iAF/NP cell viability and proliferation were performed, and the toxicity of dipyrone was determined. MTT analyses were performed at $0 \mathrm{~h}, 10$ days and 20 days.

The culture media containing dipyrone was discarded from the wells and $100 \mathrm{ml}$ MTT solution $(12 \mathrm{mM}$; prepared by adding $1 \mathrm{ml}$ sterile PBS to $5 \mathrm{mg}$ MTT) was added to each well. Cultures were incubated at $37^{\circ} \mathrm{C}$ for $2 \mathrm{~h}$ under the exclusion of light. The solution was discarded prior to the addition of DMSO, which was added to stop the reaction. Following this, wells were incubated at $37^{\circ} \mathrm{C}$ for an additional $10 \mathrm{~min}$, prior to photometric analysis of the absorbance at a wavelength of $540 \mathrm{~nm}$. The viability of the control group was assumed to be $100 \%(6,7)$.

AO/PI staining. To determine cell viability and confirm the results of the MTT assay, the nucleic acid-binding dyes AO and PI were used. AO stained all nucleated cells, whether alive or dead, generating green fluorescence. PI penetrated only dead cells with poor membrane integrity and stained nucleated cells to generate red fluorescence. When stained with AO and PI, all live nucleated cells exhibited green fluorescence and all dead nucleated cells displayed red fluorescence $(6,7)$. To prepare the AO/PI stain, $4 \mathrm{mg}$ AO (dissolved in $2 \mathrm{ml} 99 \%$ ethanol), $10 \mathrm{~g}$ sodium EDTA, $4 \mathrm{mg}$ PI and $50 \mathrm{ml}$ FBS were mixed well. Sterile distilled water was added to reach a final volume of $200 \mathrm{ml}(6,7,9)$. 
Real-time PCR analysis of CHAD, COMP, MMP-7, MMP-13, $M M P-19$ and $I L-1 \beta$ expression. Total RNA was extracted from cultured primary iAF/NP cells using the PureLink ${ }^{\mathrm{TM}}$ RNA Mini kit. The quantity of RNA was measured and $50 \mathrm{ng}$ RNA was reverse-transcribed using a high-capacity cDNA RT kit to obtain cDNA using a thermal cycler. For synthesis of cDNA, $10 \mu 1$ 10X RT buffer, $4 \mu 1$ 25X dNTP, $10 \mu 1$ 10X random primers, $5 \mu 150 \mathrm{U} / \mu 1$ reverse transcriptase, $51 \mu 1$ nuclease-free water and $20 \mu \mathrm{l}$ RNA were mixed well and held at $25^{\circ} \mathrm{C}$ for $10 \mathrm{~min}$. They were then maintained at $37^{\circ} \mathrm{C}$ for $2 \mathrm{~h}$. To determine gene expression profiles, all genes were amplified using TaqMan gene expression assays for CHAD, $\beta$-actin (ACT $\beta$ ), COMP, MMP-7, MMP-13, MMP-19 and IL-1 $\beta$. qPCR was performed on an Applied Biosystems 7300/7500 real-time PCR system (Thermo Fisher Scientific, Inc.). The reaction mixture consisted of $1 \mu 1$ TaqMan gene expression assay (probes and primers), $10 \mu 1$ TaqMan gene expression master mix, $4 \mu 1$ cDNA template and UltraPure DNase/RNase-free distilled water for each gene in MicroAmp fast optical 96-well reaction plates. The thermocycling conditions were as follows: A holding stage for $2 \mathrm{~min}$ at $50^{\circ} \mathrm{C}$, a second holding stage for $10 \mathrm{~min}$ at $95^{\circ} \mathrm{C}$ and a 40 cycles of $15 \mathrm{sec}$ at $95^{\circ} \mathrm{C}$ and $1 \mathrm{~min}$ at $60^{\circ} \mathrm{C}$. The steps were performed only once. As a result of the qPCR experiment, the relative quantity (RQ) values of each sample were obtained using the 7500 Fast-SDS program V.2.3 (Thermo Fisher Scientific, Inc.). ACT $\beta$ was used as an endogenous control to normalize the targeted gene expression. For obtaining comparative results, a reference (calibrator) sample (Group 1, $0 \mathrm{~h}$ ) was used, and RQ values were calculated using the $2^{\Delta \Delta C q}$ method $(6,7,9)$.

Statistical analyses. Minitab 16 Statistical Software was used to evaluate the data. Analysis of variance (ANOVA) was used to calculate the difference between the mean values of the data obtained. After the ANOVA test, Tukey's honestly significant difference test was used to determine which groups were different from each other or whether all groups were different from each other. Values are expressed as the mean \pm standard deviation. In the statistical analyses, a 95\% confidence interval was assumed and differences with an alpha value of $<0.05$ were considered to be statistically significant.

\section{Results}

Evaluation of AO/PI staining. The formation of the extracellular matrix structure was significantly decreased in the dipyrone-treated samples compared with that in the control group. When the dipyrone-treated cells of the intervertebral disc tissue were examined, they were observed to have lost their morphology and become rounder in shape, an indicator of cytotoxicity. Thus, cell proliferation in the cultures treated with dipyrone was decreased. However, no acute cell death was observed on AO/PI staining (Fig. 1).

Cell viability, toxicity and proliferation. Microscopic analysis indicated reduced proliferation in dipyrone-treated cultures. These results were confirmed by MTT analysis. In the drug-treated groups, cell viability and proliferation were decreased by almost half compared with those in the untreated control group. These results were statistically significant $(\mathrm{P}<0.05$; Table I).

Interpretation of $R T-q P C R$ analysis. The expression of all genes analyzed by RT-qPCR was assumed as $100 \%(R Q=1)$ on day 0 . In the untreated control group, the expression of CHAD on the tenth day increased by $\sim 3.2$-fold and IL- $1 \beta$ expression increased by $\sim 3.4$-fold. The gene expression of MMP-19 exhibited an increase with $\mathrm{RQ}=1.7$. COMP expression in the control group did not change $(\mathrm{RQ}=1.0)$, but MMP-13 $(\mathrm{RQ}=0.4)$ and MMP-7 $(\mathrm{RQ}=0.1)$ expression decreased $(\mathrm{P}<0.05)$. In the control group, on day 20 , the expression of CHAD had increased by 4.3 -fold and the gene expression of IL-1 $\beta$ increased by 7.03 -fold $(\mathrm{P}<0.05)$. The expression of MMP-13 $(\mathrm{RQ}=0.1)$ and MMP-7 $(\mathrm{RQ}=0.1)$ decreased, while the expression of COMP $(\mathrm{RQ}=1.3)$ and MMP-19 $(\mathrm{RQ}=1.5)$ exhibited a slight increase $(\mathrm{P}<0.05)$. In the dipyrone-treated cultures, gene expression stopped in a manner consistent with the morphologically observed senescence (data not shown). In the dipyrone-treated group, although, internal control $\beta$-actin gene expression was persistent no expression of the analyte genes was detected after 20 days. The cells did not die through apoptosis or any other mechanism but became senescent after dipyrone application. This result demonstrated the complete halt of cell proliferation.

\section{Discussion}

Dipyrone is a 4-MAA derivative that is commonly used as an NSAID in certain European countries, South America, South Africa and the Middle East due to its analgesic and anti-pyretic effects. Particularly in the practice of neurosurgery, studies exist on the use of this drug for the following purposes: a) In post-operative pain control, b) in the treatment of cerebral vasospasm after subarachnoid hemorrhage, c) as a neuroprotective in ischemic cerebrovascular occlusions and d) as a local anesthetic in awake craniotomies (10-12).

Different results have been reported in toxicology studies performed with dipyrone. A statistically significant weight loss has been indicated, particularly in female rats, but no changes in the mean lifespan, blood parameters or tumor development have been indicated (13). In addition, mild hemosiderosis, an increase in reticulocyte count and increase in Heinz body formation have been reported in live mammals exposed to high doses of dipyrone for 6 months (14). In a similar study, a case of aplastic anemia due to dipyrone use for 12 months was reported (15). Even though numerous adverse effects of the drug have been reported in the literature, its effects on intervertebral disc tissue cells, including NP or AF cells, have not been examined. Therefore, the present study aimed to investigate the positive or negative effects of dipyrone on intact intervertebral disc tissue cells at the pharmaco-molecular level.

Most cytotoxicity studies used experimental setups involving tissues of living mammalian subjects $(16,17)$. However, the results obtained with animal tissues may be different from those obtained with human tissue due to differences in sensitivity (18). In numerous studies where animal tissues were not used, commercial cell lines were used $(19,20)$. However, in systems such as cell lines, one type of cell is used, and in such commercial cell lines, no complex coordination mechanisms with the 
Table I. Grouping of Tukey test data after ANOVA performed in 95\% confidence interval between control and dipyrone groups.

A, MTT viability assay (ANOVA)

\begin{tabular}{lccrr}
\hline Group & DF & Adj SS & Adj MS & F-value \\
\hline Incubation times (h) & 1 & 0.088621 & 0.088621 & 231.08 \\
Non-treated with dipyrone & 1 & 0.001860 & 0.001860 & 4.85 \\
Dose & 1 & 0.053464 & 0.053464 & 0.036 \\
\hline
\end{tabular}

B, MTT viability assay (Tukey's honestly significant differences test)

\begin{tabular}{llcc}
\hline Group/incubation time & N & Mean \pm standard deviation & Grouping \\
\hline Control group 20 days & 8 & $0.4120 \pm 0.034$ & A \\
Control group 10 days & 8 & $0.3150 \pm 0.008$ & B \\
Dipyrone 10 days & 8 & $0.2915 \pm 0.013$ & B \\
Dipyrone 20 days & 8 & $0.2250 \pm 0.011$ & C \\
\hline
\end{tabular}

From A to C, with A being the highest and C the lowest cell proliferation and viability. ANOVA, analysis of variance; DF, degrees of freedom; Adj, adjusted; SS, Sum of square; MS, mean square.
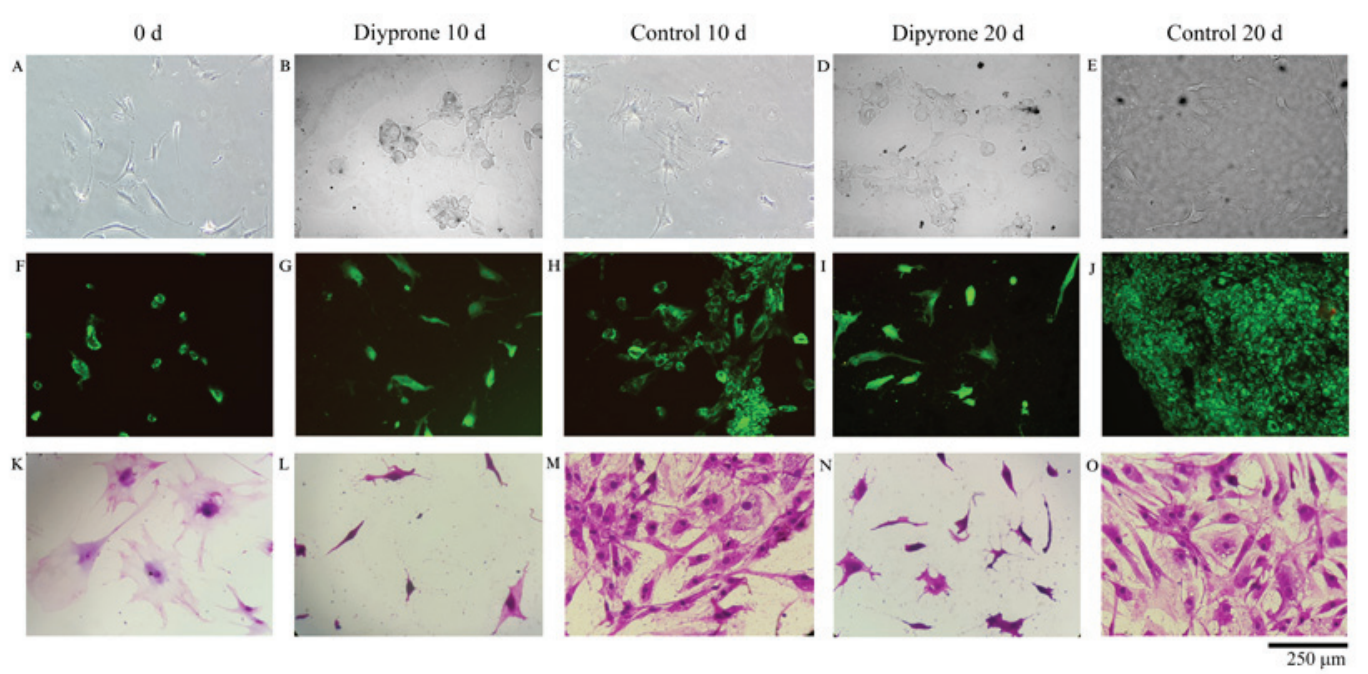

Figure 1. Evaluation of nucleus pulposus and annulus fibrosus cells through inverted light/fluorescent microscopy. Images of (A-E) the inverted light microscope and (F-J) acridine orange/propidium iodide staining were taken at a magnification of x10, x20 and x40. Images of (K-O) Giemsa staining were taken at a magnification of $\mathrm{x} 20$.

microenvironment involving other tumor-associated cells are present. As a result, the in vitro test results may not resemble in vivo conditions and may become even more controversial, since the cell does not interact with factors such as the extracellular matrix. In addition, since the genetic structure of the cells in the cell line would have been modified, they would not carry the genotypic and/or phenotypic characteristics that they have in the human body (21). Therefore, the present study did not use any commercial cell lines or cells isolated from animal tissues. The study was performed on primary cell cultures isolated from intact human intervertebral disc tissues. This may be one of the aspects in which the results of the present study are superior.

Certain studies have provided evidence that dipyrone applied at low doses was not toxic but had a cytoprotective effect. Pompeia et al (8) evaluated the effect of dipyrone on the viability in human leukocyte cell lines upon the following apoptotic treatments: Arachidonic acid (AA), cycloheximide (CHX), tumor necrosis factor (TNF) and ultraviolet (UV) irradiation. They investigated different dose-dependent effects of dipyrone. First, they reported that it was cytotoxic and caused apoptosis at high concentrations (beyond $300 \mu \mathrm{M}$ ). Furthermore, they indicated that it was cytoprotective at lower concentrations (37.5-300 $\mu \mathrm{M})$ and that it delayed the loss of membrane integrity generated by AA (100-200 $\mu \mathrm{M})$, UV irradiation and the cytotoxicity of $\mathrm{CHX}(25-50 \mu \mathrm{M})$. They did not identify any effect of dipyrone on TNF-induced cytotoxicity $(250 \mathrm{ng} / \mathrm{ml})$. They emphasized that the cytoprotective effect of dipyrone was associated with a decrease in DNA fragmentation 
when assessed by electrophoresis and flow cytometry of genomic DNA. They also underscored that the cytoprotective effect on leukocyte apoptosis occurred at concentrations that are common for the major active metabolite of the drug (8). Arkhipchuk et al (22) applied dipyrone and acetylsalicylic acid drugs to different systematic groups formed from plants, invertebrates and vertebrates. They evaluated the toxicity, cytotoxicity and genotoxicity of the drugs on those different systematic groups. When the pharmaceutical substances were administered to live mammalian cells, they were applied at a dose resembling the $\mathrm{IC}_{50}$, which was half of the concentration of the substance known to be inhibitory. They reported that dipyrone had acute toxic effects when applied at a concentration of $6.25 \%$. After 30-360 min of exposure of the respective organism to the drug, the nucleolar size in plant and animal cells (i.e., the transcription activity of the ribosomal genes) changed. Furthermore, they also indicated that dipyrone gave rise to nucleolar structural damage in $90 \%$ of hydra cells at as early as $30 \mathrm{~min}$ of exposure (22). CHAD, a continuously expressed NP-specific marker, is known to be linked with the development of the spinal cord and dorsal column $(6,7,9)$. COMP is the most well-known marker amongst the degradation markers. Increased levels of this marker are thought to indicate the progression of osteoarthritis and aging of the tissues. COMP, a non-aggrecan and non-collagenous marker, indicates degradation of cartilage. However, studies have indicated that COMP also occurs in bones, ligaments, tendons and in the vascular smooth muscles. However, COMP expression was not identified in NP or AF cells. The utility of COMP as a marker has also been investigated in molecular studies regarding lumbosacral spine disc space narrowing, intervertebral disc tissue and lower back symptoms (23-26).

MMPs, the enzymes responsible for the destruction of extracellular matrix proteins and organogenesis, the process of growth and normal tissue regeneration, have essential functions in maintaining physiological incidents in the organism. They perform these functions through a balance between MMP activity and specific endogenous tissue inhibitors. The shift of this balance to MMP activity leads to matrix destruction and pathophysiological events (27). While MMP synthesis and activity is low in healthy tissues, its level increases in numerous pathological and/or adverse conditions, including inflammatory diseases, tumor progression and metastasis; this increase causes tissue destruction (28).

Since 1991, MMPs in the intervertebral disc cells have been known to cause degeneration of healthy intact disc tissue (29). As is known, large collagen types are present in NP and AF tissues. The structure of these collagens and their association with each other have a vital role in the mechanical function of the disc. These collagen molecules may only be degraded by specific enzymes, primarily MMPs. MMPs are the major enzymes in the catabolism of collagen molecules and differ regarding their substrate specificity. MMPs degrade all known matrix components (29). Degenerated discs are more vascular than normal discs, and vascular structures are known to produce MMPs. Although immunohistochemistry provides limited information, when considering the ratio of disc cells to vascular cells, most MMPs are produced by disc cells. The high MMP levels in the herniated discs indicate that the MMPs are naturally responsible for the repair of disc herniation (29).
Yurube et al (30) investigated the degeneration of intervertebral disc tissue in rats, which were used as experimental live mammals. They reported that MMP-7 and MMP-13 are catabolic genes associated with the degeneration of disc tissue. MMP-13, classified into the group of collagenases, is an enzyme with the ability to break down intact interstitial collagen molecules (31). MMP-7, also known as matrilin, is capable of degrading non-collagenase proteins, including proteoglycans and MMP-3. MMP-7 is able to break down the intermolecular network between collagen fibrils, as it breaks down denatured collagen molecules (32).

MMP-19, which is known to hydrolyze certain basal membrane proteins, is also referred to as RASI-1 (33). The human MMP-19 gene encodes a protein that has a role in normal physiological processes, including embryonic development, reproduction and tissue remodeling, as well as in the degradation of extracellular matrix in processes associated with various diseases, e.g. arthritis and metastasis. The encoded protein is secreted as an inactive proprotein that is activated upon cleavage by extracellular proteases (34).

In their study regarding MMP-19, Gruber et al (35) reported that no previous studies had assessed the effects of MMP-19 on the extracellular matrix components of the disc, and that MMPs degrade the extracellular matrix components of the disc. They indicated that in other tissue types, MMP-19 was implicated in the proteolysis of insulin-like growth factor (IGF) binding protein-3, thus exposing this protein to make it available to influence cell behavior. They also reported that MMP-19 inhibited capillary-like formation and thus has a role in the avascular nature of the disc. They examined normal discs obtained from subjects aged $0-10$ years $(n=6)$ and disc samples obtained from control donors or surgical patients ( $n=20$; mean age, 40.2 years) for immunolocalization of MMP-19. They classified the discs as Thompson grade I $(n=6)$, II $(n=5)$, III $(n=8)$, IV $(n=5)$ and V $(n=1)$ and analyzed them. The results indicated that MMP-19 was uniformly localized in the outer AF structure of discs from young subjects; however, MMP-19 localization was rarely observed in outer and inner AF cells in discs from adult donors and surgical patients. In addition, the highest expression of MMP-19 was observed in discs from younger subjects, while it was low in disks from older subjects or degenerating discs. They concluded that MMP-19 regulates IGF-mediated proliferation in tissues other than discs and that aging or degenerating discs may contribute to an age-associated decreases in disc cell numbers (35).

Over the last two decades, it has been reported that cytokines are produced by NP cells in the intervertebral disc structure, mainly chondrocytes, histiocytes and fibroblasts (36). IL-1 $\beta$ has been reported to have a role in disc metabolism and to be the predominant proinflammatory cytokine of the disc. The ability of IL-1 $\beta$ to convert chondrocytes from featuring anabolic activity to catabolic activity has been indicated (36). In this manner, it causes degradation and increases angiogenetic factors to facilitate angiogenesis. IL-1 $\beta$ increases proteoglycan release and destructive enzymes (36). In addition, IL-1 $\beta$ stimulates the release of pain mediators, including prostaglandin-E2, from intervertebral disc cells. IL-1 $\alpha$ has been reported to enhance the synthesis of MMPs and nitric oxide, as well as directly increase catabolism of 
disc proteoglycans, providing a basis for degeneration. IL-1 $\beta$ has been reported to have a role in disc metabolism and is the predominant proinflammatory cytokine of the disc (36).

A recent study reported that IL-1 $\beta$ caused apoptosis of AF cells and had negative effects on intervertebral disc tissue cells (37). Rats were used as live mammals in the study, and IL-1 $\beta$ induction was reported to significantly reduce chondroitin sulfate glycosyltransferases-1/2/3 at the mRNA level in NP cells (37). In addition, inflammatory cytokines including IL-1 $\beta$ stimulated mRNA-194 and mRNA-515, targeted CHSY-1/2/3 mRNA and significantly degraded translation and downstream chondroitin sulfate accumulation in the mechanism of intervertebral disc degeneration (38).

Therefore, proliferation and cytotoxicity analysis were performed in the present study with the cell cultures of the non-degenerate, intact intervertebral disc tissue after drug administration. In addition, the levels of CHAD, COMP, MMP-7, MMP-13, MMP-19 and IL-1 $\beta$ were examined and compared between the non-drug-treated control groups and the dipyrone-treated groups. This was to determine whether the cells isolated from the non-degenerated intact intervertebral disc tissue were inclined to degenerate after application of the active pharmacological agent dipyrone.

The present study investigated whether dipyrone had any cytotoxic effect on intact intervertebral disc tissue cells. This situation was comparatively investigated in the untreated and dipyrone-treated cultures. No acute cell death was observed, even when a deterioration of the cell morphology was observed in the dipyrone-treated samples during the experiments. However, a suppression of cell proliferation was observed. Whether this was associated with a poorly developing microenvironment was examined by comparing the gene expression of CHAD and COMP with that of MMP-19. CHAD and COMP proteins secreted from AF/NP cells constitute the extracellular matrix and contribute to the formation of a healthy microenvironment in the intervertebral disc tissue $(6,7,39)$. COMP is also important in cross-linking, along with other extracellular matrix elements. MMP-19 is an enzyme that cleaves COMP. IL-1 $\beta$ is an inflammatory cytokine that was increased during the degeneration of intervertebral disc tissue cells. The increase in IL-1 $\beta$ expression causes an increase in MMP-7 and MMP-13. Therefore, the gene expression of MMP-7 and MMP-13, along with that of IL-1 $\beta$, was investigated to determine whether the degenerated cell morphology may be indicative of degeneration.

In the present study, all the genes in the control group and the $\beta$-actin gene (which was used as an internal control) in the dipyrone-treated cultures, continued to be expressed. Dipyrone-treated cultures were only obtained from 6 patients, which serves as a limitation of the current study. Although analyses were repeated to eliminate this limitation, gene expression in the cultures were significantly low, which did not allow for their detection via respective assays. Furthermore, the number of patients could not be augmented due to the following reasons: Difficulty in obtaining intact tissue from patients, a low number of patients with spinal trauma from whom intact IVD tissue could be extracted and difficulty in obtaining Ethics Committee approval and written consent forms.
In the present study, cell proliferation in the drug-treated group decreased compared with that in the untreated control group. This indicated that the dipyrone agent had an inhibitory effect on the intervertebral disc tissue cells $(\mathrm{P} \leq 0.05)$. In addition, no gene expression, as was the case compared with the untreated group at the same incubation time, was observed on the tenth and twentieth day in the dipyrone-treated experimental groups. The cells did not die through apoptosis or any other mechanism but became senescent after dipyrone application; their proliferation was suppressed and stopped. A clearer result may therefore be drawn similar study on a larger number of patients.

The most important limitation of the present study was the fact that dipyrone is a prodrug and thus does not affect the enzyme cyclooxygenase in vitro. Therefore, investigation of the gene expression in living mammal subjects with an in vivo experimental design or in the human body is of significant importance. An in vivo study using an animal model is required to immunohistochemically evaluate the expression of MMP and proteins associated with apoptotic pathways.

Although no cell death was observed in the analyses of AF/NP cells obtained from intact tissue on the twentieth day, suppressed proliferation was present and the gene expression was suppressed. For this reason, dipyrone, which is frequently used by clinicians as an analgesic, anti-pyretic and anti-spasmodic, should be applied with caution, since it may slow down the healing process.

\section{Acknowledgements}

Not applicable.

\section{Funding}

No funding was received.

\section{Availability of data and materials}

The data and materials generated/analyzed in the present study are available from the corresponding author on reasonable request.

\section{Authors' contributions}

FA conceived and designed the current study, wrote the manuscript, acquired patient data, analyzed and interpreted the data, performed ELISA and performed microscopic evaluation. DS analyzed and interpreted the data, prepared the human primary cell culture and performed PCR analysis. IY and NuK prepared the human primary cell culture, performed inverted light microscopy, analyzed PCR results and prepared/stored dipyrone. HO, IY and NuK performed statistical analysis and wrote the manuscript. ATS, YEK, NeK and YA selected the patients who met the inclusion criteria and performed statistical analyses. FSA, NuK, NeK, YA, TC and OA diagnosed and performed patient, and removed tissue for laboratory analysis. OA, HO, NuKa, DYS, IY, YEK and FSA prepared the manuscript and critically revised it for important intellectual content. All authors have read and approved the final version of the manuscript. 


\section{Ethics approval and informed consent}

The present study was approved by the ethics committee of the Istanbul Medipol University School of Medicine (Istanbul, Turkey). Written informed consent was obtained from all subjects.

\section{Patient consent for publication}

Not applicable

\section{Competing interests}

The authors declare that they have no competing interests.

\section{References}

1. Yilmaz I and Ulugol A: The effect of nitric oxide synthase inhibitors on the development of analgesic tolerance to dipyrone in mice. Int J Neurosci 119: 755-764, 2009.

2. Garcia S, Canoniero M, Lopes G and Soriano AO: Metamizole use among Hispanics in Miami: Report of a survey conducted in a primary care setting. South Med J 99: 924-926, 2006.

3. Dilmen OK, Akcil EF, Tunali Y, Karabulut ES, Bahar M, Altindas F, Vehid H and Yentur E: Postoperative analgesia for supratentorial craniotomy. Clin Neurol Neurosurg 146: 90-95, 2016.

4. Claros OR, Silva CH, Consolmagno H, Sakai AT, Freddy R and Fugita OE: Current practices in the management of patients with ureteral calculi in the emergency room of a university hospital. Clinics (Sao Paulo) 67: 415-418, 2012.

5. Florentino IF, daSilva DP, Martins JL, da Silva TS, Santos FC, Tonussi CR, Vasconcelos GA, Vaz BG, Lião LM, Menegatti R and Costa EA: Pharmacological and toxicological evaluations of the new pyrazole compound (LQFM-021) as potential analgesic and anti-inflammatory agents Inflammopharmacology 24: 265-275, 2016.

6. Sirin DY and Karaarslan N: Evaluation of the effects of pregabalin on chondrocyte proliferation and CHAD, HIF-1 $\alpha$, and COL2A1 gene expression. Arch Med Sci 14: 1340-1347, 2018.

7. Karaarslan N, Yilmaz I, Sirin DY, Ozbek H, Kaplan N, Kaya YE, Akyuva Y, Gurbuz MS, Oznam K and Ates O: Does pregabalin used in the treatment of neuropathic pain damage intervertebral disc tissue? Exp Ther Med 16: 1259-1265, 2018

8. Pompeia C, Boaventura MF and Curi R: Antiapoptotic effect of dipyroneon HL-60, Jurkat and Raji cell lines submitted to UV irradiation, arachidonic acid and cycloheximide treatments. Int Immunopharmacol 1: 2173-2182, 2001.

9. Akyuva Y, Karaarslan N, Yilmaz I, Ozbek H, Sirin DY, Gurbuz MS, Kaya YE, Kaplan N and Ates O: How scaffolds, which are polymeric drug delivery systems allowing controlled release, can be tested in human primary nucleus pulposus and annulus fibrosus cell cultures? Merit Res J Med Med Sci 5: 477-487, 2017.

10. Silav G, Ergün H, Dolgun H, Sancak T, Sargon MF and Egemen N: Dipyrone attenuates cerebral vasospasm after experimental subarachnoid hemorrhage in rabbits. J Neurosurg Sci 61: 380-387, 2017.

11. Zhang Y, Wang X, Baranov SV, Zhu S, Huang Z, Fellows-Mayle W, Jiang J, Day AL, Kristal BS and Friedlander RM: Dipyrone inhibits neuronal cell death and diminishes hypoxic/ischemic brain injury. Neurosurgery 69 942-956, 2011

12. Grossman R, Ram Z, Perel A, Yusim Y, Zaslansky R and Berkenstadt $\mathrm{H}$ : Control of postoperative pain after awake craniotomy with local intradermal analgesia and metamizol. Isr Med Assoc J 9: 380-382, 2007.

13. Donaubauer HH, Kief H, Kramer M, Krief K, Mayer D and Schütz E: Investigations on the carcinogenicity of dipyrone in rats. Toxicol App Pharmacol 81: 443-451, 1985.

14. Kramer M: Chronic toxicity of pyrazolones: The problem of nitrosation. Br J Clin Pharmacol 10 (Suppl 2): S313-S317, 1980

15. Maj S and Lis Y: The incidence of metamizole sodium-induced agranulocytosis Poland. J Int Med Res 30: 488-495, 2002.
16. Giorgi M, Aupanun S, Lee HK, Poapolathep A, Rychshanova R, Vullo C, Faillace V and Laus F: Pharmacokinetic profiles of the active metamizole metabolites in healthy horses. J Vet Pharmacol Ther 40: 165-171, 2017.

17. Schütter AF, Tünsmeyer J and Kästner SB: Influence of metamizole on 1) minimal alveolar concentration of sevoflurane in dogs and 2) on thermal and mechanical nociception in conscious dogs. Vet Anaesth Analg 43: 215-226, 2016.

18. Yaşar Şirin D, Yılmaz İ, İsyar M, Öznam K and Mahiroğulları M: Does leukocyte-poor or leukocyte-rich platelet-rich plasma applied with biopolymers have superiority to conventional platelet-rich plasma applications on chondrocyte proliferation? Eklem Hastalik Cerrahisi 28: 142-151, 2017.

19. Bundscherer AC, Malsy M, Gruber MA, Graf BM and Sinner B: Acetaminophen and metamizole induce apoptosis in HT 29 and SW 480 colon carcinoma cell lines in vitro. Anticancer Res 38: 745-751, 2018.

20. Malsy M, Graf B and Bundscherer A: Effects of metamizole, MAA, and paracetamol on proliferation, apoptosis, and necrosis in the pancreatic cancer cell lines PaTu $8988 \mathrm{t}$ and Panc-1. BMC Pharmacol Toxicol 18: 77, 2017.

21. Guzelant AY, Isyar M, Yilmaz I, Sirin DY, Cakmak S and Mahirogullari M: Are chondrocytes damaged when rheumatologic inflammation is suppressed? Drug Chem Toxicol 40: 13-23, 2017.

22. Arkhipchuk VV, Goncharuk VV, Chernykh VP, Maloshtan LN and Gritsenko IS: Use of a complex approach for assessment of metamizole sodium and acetylsalicylic acid toxicity, genotoxicity and cytotoxicity. J Appl Toxicol 24: 401-407, 2004.

23. Rutges J, Creemers LB, Dhert W, Milz S, Sakai D, Mochida J, Alini $\mathrm{M}$ and Grad S: Variations in gene and protein expression in human nucleus pulposus in comparison with annulus fibrosus and cartilage cells: potential associations with aging and degeneration. Osteoarthritis Cartilage 18: 416-423, 2010.

24. van den Akker GG, Surtel DA, Cremers A, Richardson SM, Hoyland JA, van Rhijn LW, Voncken JW and Welting TJ: Novel immortal cell lines support cellular heterogeneity in the human annulus fibrosus. PLoS One 11: 0144497, 2016.

25. Zhang YG, Guo X, Sun Z, Jia G, Xu P and Wang S: Gene expression profiles of disc tissues and peripheral blood mononuclear cells from patients with degenerative discs. J Bone Miner Metab 28: 209-219, 2010.

26. Goode AP, Marshall SW, Kraus VB, Renner JB, Stürmer T, Carey TS, Irwin DE and Jordan JM: Association between serum and urine biomarkers and lumbar spine individual radiographic features: The johnston county osteoarthritis project. Osteoarthritis Cartilage 20: 1286-1293, 2012.

27. Yilmaz I, Gokay NS, Bircan R, Saracoglu GV, Dervisoglu S and Gokce A: How different methodologies of harvesting and analysing the samples affect the test results in determining joint mediators. Arthritis 2013: 631959, 2013.

28. Gokay NS, Yilmaz I, Komur B, Demiroz AS, Gokce A, Dervisoglu S and Gokay BV: A Comparison of the effects of neuronal nitric oxide synthase and inducible nitric oxide synthase inhibition on cartilage damage. Biomed Res Int 2016: 7857345, 2016.

29. Goupille P, Jayson MI, Valat JP and Freemont AJ: Matrix metalloproteinases: The clue to intervertebral disc degeneration? Spine (Phila Pa 1976) 23: 1612-1626, 1998.

30. Yurube T, Takada T, Suzuki T, Kakutani K, Maeno K, Doita M, Kurosaka $M$ and Nishida K: Rat tail static compression model mimics extracellular matrix metabolic imbalances of matrix metalloproteinases, aggrecanases, and tissue inhibitors of metalloproteinases in intervertebral disc degeneration. Arthritis Res Ther 14: R51, 2012.

31. Weiler C, Nerlich AG, Zipperer J, Bachmeier BE and Boos N: 2002 SSE Award Competition in Basic Science: Expression of major matrix metalloproteinases is associated with intervertebral disc degradation and resorption. Eur Spine J 11: 308-320, 2002.

32. Roberts S, Caterson B, Menage J, Evans EH, Jaffray DC and Eisenstein SM: Matrix metalloproteinases and aggrecanase: Their role in disorders of the human intervertebral disc. Spine (Phila Pa 1976) 25: 3005-3013, 2000.

33. Sedlacek R, Mauch S, Kolb B, Schätzlein C, Eibel H, Peter HH, Schmitt J and Krawinkel U: Matrix metalloproteinase MMP-19 (RASI-1) is expressed on the surface of activated peripheral blood mononuclear cells and is detected as an autoantigen in rheumatoid arthritis. Immunobiology 198: 408-423, 1998.

34. NCBI: Matrix metallopeptidase 19 [Homo sapiens (human)]. https://www.ncbi.nlm.nih.gov/gene/4327. Accessed March 3, 2018. 
35. Gruber HE, Ingram JA and Hanley EN Jr: Immunolocalization of MMP-19 in the human intervertebral disc: Implications for disc aging and degeneration. Biotech Histochem 80: 157-162, 2005.

36. Nishida Y, D'Souza AL, Thonar EJ and Knudson W: Stimulation of hyaluronan metabolism by interleukin-1alpha in human articular cartilage. Arthritis Rheum 43: 1315-1326, 2000.

37. Hu B, Xu C, Tian Y, Shi C, Zhang Y, Deng L, Zhou H, Cao P, Chen $\mathrm{H}$ and Yuan W: Inflammatory microRNA-194 and -515 attenuate the biosynthesis of chondroitin sulfate during human intervertebral disc degeneration. Oncotarget 8: 49303-49317, 2017.
38. Lv FJ, Peng Y, Lim FL, Sun Y, Lv M, Zhou L, Wang H, Zheng Z Cheung KMC and Leung VYL: Matrix metalloproteinase 12 is an indicator of intervertebral disc degeneration co-expressed with fibrotic markers. Osteoarthritis Cartilage 24: 1826-1836, 2016.

cc) (i) $\ominus$ This work is licensed under a Creative Commons Attribution-NonCommercial-NoDerivatives 4.0 International (CC BY-NC-ND 4.0) License. 